\title{
PENERAPAN METODE DEMONSTRASI BERBANTU MEDIA AUDIO VISUAL TERHADAP GERAKAN SALAT SISWA KELAS II SDN 2 NANGA MAN
}

\author{
Trisnawati $^{1}$, M. Akip ${ }^{2}$, Khairil Akbar ${ }^{3}$ \\ ${ }^{1}$ Mahasiswa Lulusan Program Studi PGSD \\ ${ }^{2,3}$ Dosen STKIP Melawi
}

Jl. RSUD Melawi km. 04 Kec.Nanga Pinoh Kab. Melawi Kalimantan Barat watitrisna950@gmail.com, m.akipstkip@id.com, khairilakbar89@gmail.com

\begin{abstract}
This study aims to determine the ability of students to practice the movement of prayer in the subjects of Islamic Education (PAI) class II SDN 2 Nanga Man. The research was carried out based on the background of the problem students were not yet skilled in practicing the prayer movement. Through this research, students are expected to be able to practice the movement of prayer well and correctly so that it can be useful in everyday life. This study used a demonstration method assisted by audio visual media in class II of SDN 2 Nanga Man. This type of research is an experiment using the form of Pretest-Posttest Design One-Group. The population in this study were second grade students of SDN 2 Nanga Man using a total sampling technique or saturated sample of 17 people consisting of 8 female students and 9 male students. The results of this study obtained an average score of 54.65 and posttest pretest 78.86. Hypothesis test results from the Wilcoxon match pair test on the prayer movement observation sheet show that the value $1.96>-3.622$ or $\mathrm{Z}$ table $>\mathrm{Z}$ count so that $\mathrm{H} 0$ is rejected and $\mathrm{Ha}$ is accepted. So it can be concluded that there are differences using the demonstration method assisted by audio visual media before and after being applied to the prayer movement to students, especially in PAI learning in class II of SDN 2 Nanga Man.
\end{abstract}

Keywords: Audio Visual Media Assisted Demonstration and Salat Movement

\begin{abstract}
Abstrak: Penelitian ini bertujuan untuk mengetahui bagaimana gerakan salat siswa sebelum dan sesudah diterapkan metode demonstrasi berbantu media audio visual pada mata pelajaran Pendidikan Agama Islam (PAI) siswa kelas II SDN 2 Nanga Man. Penelitian dilaksanakan berdasarkan latar belakang masalah siswa belum terampil dalam mempraktikan gerakan salat. Melalui penelitian ini diharapkan siswa dapat mempraktikan gerakan salat dengan baik dan benar sehingga bisa berguna di kehidupan sehari-hari. Penelitian ini menggunakan metode demonstrasi berbantu media audio visual pada siswa kelas II SDN 2 Nanga Man. Jenis penelitian ini adalah eksperimen dengan menggunakan bentuk Design One-Group Pretest-Posttest. Populasi dalam penelitian ini siswa kelas II SDN 2 Nanga Man dengan menggunakan teknik total sampling atau sampel jenuh yang berjumlah 17 orang terdiri dari 8 siswa perempuan dan9siswa laki-laki. Hasil penelitian ini diperoleh skor rata-rata pretest 54,65 dan posttest 78,86. Hasil uji hipotesis dari uji wilcoxon match pair test pada lembar pengamatan gerakan salat siswa menunujukan nilai $1.96>-3.622$ atau $\mathrm{Z}$ table $>\mathrm{Z}$ hitung sehingga H0di tolak dan Ha di terima . Jadi dapat disimpulkan bahwa terdapat perbedaan menggunakan metode demonstrasi berbantu media audio visual sebelum dan sesudah diterapkan terhadap gerakan salat pada siswa, khususnya pada pembelajaran PAI di kelas II SDN 2 Nanga Man.
\end{abstract}

Kata Kunci: Demonstrasi Berbantu Media Audio Visual dan Gerakan Salat. 
$\mathrm{P}$

endidikan agama mengupayakan manusia mampu untuk mewujudkan tujuan penciptanya. Manusia diciptakan agar mengetahui hakikat Tuhannya, mengesakan, beribadah kepada tuhannya, dan mau menghambakan diri dengan menjalankan seluruh perintah dan menjauhi semua larangan. Pembelajaran agama di sekolah pada umumnya merupakan usaha sadar untuk menyiapkan siswa agar mengetahui, terampil, dan melaksanakan perintah agama (Susanto, 2016:279).

Kurikulum pendidikan agama Islam pada jenjang pendidikan dasar dimaksudkan untuk meningkatkan potensi spritual peserta didik agar dapat mengenal dan membiasakan diri dalam menjalankan ajaran agama, serta dapat memahami, meyakini, dan mengamalkan ajaran agama islam dengan baik. Dalam hal ini pelaksanaan kurikulum di setiap jenjang pendidikan, pendidikan agama islam merupakan pelajaran wajib harus ada dan diterima oleh siswa. Mengingat akan pentingnya pendidikan agama islam bagi anak usia sekolah dasar karena pada usia inilah peranan agama pada anak akan lebih tertananam dan terbawa pada kehidupan dimasa mendatang. Maka dengan itu di sekolah Dasar Negeri 2 Nanga Man juga menerapakan pendidikan agama Islam sebagai salah satu pelajaran wajib di sekolah. Pelaksanaan pembelajaran yang dilaksanakan diharapkan dapat mencapai 30| JPD, p - I S S N : 2252 - 8156 tujuan dari pembelajaran agama Islam untuk tingkat sekolah dasar. Adapun tujuan yang dimaksud ialah, penanaman rasa agama kepada peserta didik, perasaan cinta terhadap Allah dan Rasulnya, memperkenalkan ajaran Islam seperti (rukun Islam dan rukun iman), membiasakan anak berakhlah mulia, melatih anak dalam beribadah yang bersifat praktis seperti (salat dan puasa), dan membiasakan contoh teladan yang baik. Seiring dengan tercapai tujuan pembelajaran agama di sekolah, semoga dengan telah diterapkan pendidikan agama islam menjadikan mereka sebagai manusia yang baik kedepannya.

Menjalani kehidupan sebagai seorang muslim pasti memiliki dasar hukum dalam bermadzhab (mengikuti jalan/mengikuti metode) dalam berpikir salah seorang mujtahid mengistinbathkan hukum dari sumber aslinya, yaitu al-qur'an dan hadits. Dari segi formal, mayoritas muslim di indonesia adalah madzhab imam syafi'i. Namun secara substansial, beberapa madzhab yang lain juga dikaji dipelajari bahkan diterapkan oleh sebagian muslim di indonesia terutama dari kalangan yang mengerti agama (ulama dan intelektual). Maka dari itu tuntunan gerakan salat yang akan peneliti gunakan dalam penelitian yaitu berdasarkan madzhab imam syafi' $i$.

Berdasarkan observasi peneliti melihat langsung siswa mempraktikkan e - I S S N : $2579-3993$ 
gerakan salat dan peneliti melakukan wawancara dengan guru mata pelajaran Pendidikan Agama Islam (PAI). Yang telah peneliti laksanakan terhitung sejak tanggal 1 s/d 8 Februari 2019 di SDN 2 Nanga Man. Terdapat beberapa kesenjangan dalam pembelajaran diantaranya yaituada siswa yang malas dalam menghafal, terdapat beberapa siswa yang kurang terampil dalam memperaktekan gerakan salat, beberapa siswa tidak serius ketika proses belajar, dan dalam penerapan metode guru belum menggunakan media audio visual sebagai alat bantu dalam proses pembelajaran. Untuk mengatasi hal tersebut maka peneliti mencoba untuk mencari solusi yang tepat agar dapat mengatasi permasalahan yang telah dipaparkan di atas. Agar siswa akan lebih mudah untuk memahami materi tentang salat dan mengenal gerakangerakan dalam salat. Salah satu alternatif yang dipilih oleh peneliti adalah dengan menerapkan suatu metode pembelajaran dengan berbantuan media.

Baik atau tidaknya suatu pemilihan metode dan media pembelajaran akan sangat tergantung pada tujuan pembelajaranya, kesesuaian dengan materi yang disampaikan, tingkat perkembangan siswa, kemampuan guru dalam mengelola proses pembelajaran. Sehingga pengoptimalan sumber-sumber belajar yang ada. Memahami permasalahan tersebut, peneliti berusaha mencari metode dan media pembelajaran yang dirasa tepat untuk diaplikasikan pada pembelajaran pendidikan agama islam. Agar siswa dapat memahami materi yang diajarkan secara menyeluruh, sehingga akan dapat mempermudah siswa dalam mengenal setiap gerakan-gerakan salat. Peneliti ingin selain penerapan suatu metode juga akan ditunjang media untuk mempermudah dan memperjelas dalam penyampaian materi saat kegiatan pembelajaran.

Adapun metode pembelajaran yang akan digunakan adalah metode demonstrasidengan berbantuan media audio visual. Metode pembelajaran demonstrasi adalah suatu cara mengajar di mana guru menampakan suatu benda nyata, benda tiruan, atau suatu peroses dari materi yang diajarkan kepada seluruh siswa, Roestiyah (dalam Huda, 2017:231). Hal ini juga berarti bahwa demonstrasi adalah cara penyajian pelajaran dengan memperagakan dan mempertunjukan suatu proses atau situasi secara langsung di depan seluruh siswa. Dengan metode demonstrasi, siswa dapat mengamati dengan saksama apa yang terjadi serta bagaimana prosesnya. Selain itu untuk mempermudah dan memperjelas penerapan metode demonstrasi, di sini akan dikolaborasikan pada media audio visual. Media audio visual adalah pembelajaran yang disertai interactive video, yaitu suatu sistem penyampaian pengajaran di mana 31| J P D, p- I S S N : 2252-8156, e - IS S N : 2579-3993 
materi yang penyerapannya melalui pandangan dan pendengaran. Penyajian materi pada media ini berupa video rekaman yang disajikan dengan pengendalian laptop kepada penonton (siswa).

Pada pelaksanaannya sebelum menggunakan bantuan video gerakan salat terlebih dahulu guru akan menjelaskan materi dengan mendemonstrasikan sendiri gerakan salat di depan siswa kemudian akan didemonstrasikan pula oleh siswa. Penerapan metode dengan berbantuan media diharapkan dapat dijadikan sebagai sarana dalam mempermudah memahami materi dan memperjelas mengenal setiap gerakan salat secara saksama oleh siswa saat proses pembelajaran berlangsung. Karena dengan ini selain siswa mendapatkan informsi atau pengetahuan dari guru juga dapat siswa temukan melalui penggunaan media. Pembelajaran berbantu media ini dapat melibatkan siswa secara langsung sehingga kegiatan belajar tidak hanya perpusat pada guru sebagai fasilitator, dan siswa juga dapat termotivasi untuk mengikuti pembelajaran dengan rasa keingintahuan yang berkelanjutan. Yang terpenting adalah pesan dan informasi disiapkan untuk kebutuhan dan kemampuan belajar seorang serta dikembangkan agar siswa berpartisipasi dengan aktif selama proses belajar. Dengan media tersebut terciptalah lingkungan pengajaran yang interaktif yang memberikan respon terhadap kebutuhan belajar siswa dengan jalan menyiapkan kegiatan belajar yang aktif guna menjamin terjadinya belajar.

Dengan menggunakan metode pembelajarandemonstrasiberbantu media audio visual diharapkan dapat mempengaruhi kemampuan siswa dalam melakukan gerakan salat setelah proses pembelajaran. Dengan demikian, maka peneliti merasa perlu untuk mengadakan suatu penelitian dengan judul "Penerapan Metode Demonstrasi Berbantu Media Audio Visual Terhadap Gerakan Salat Siswa Kelas II Mata Pelajaran Pendidikan Agama Islam (PAI) Siswa SDN 2 Nanga Man”.

Tujuan dari penelitian ini adalah untuk mengetahui bagaimana pengaruh metode demonstrasi berbantu media audio visual sebelum dan sesudah diterapkan metode demonstrasi berbantu media audio visual terhadap gerakan salat siswa.

\section{METODE PENELITIAN}

Pendekatan yang dalam penelitian ini adalah pendekatan kuantitatif, karena untuk mengetahui hasil dari penelitian ini, data dari hasil pengamatan harus diproses menggunakan analisis statistik terlebih dahulu. Jenis penelitian yang digunakan dalam penelitian ini adalah Pre Experimental Design. Dikatakan demikian karena desain ini belum merupakan eksperimen yang sungguh-sungguh sebab - I S S N : 2579 - 3993 
masih terdapat variabel luar yang ikut berpengaruh terhadap terbentuknya variabel dependen.

Pada desain ini peneliti menggunakan bentuk One Group Pretest-posttest Design. Pada desain ini terdapat pretest sebelum perlakuan, dengan demikian maka hasil perlakuan dapat diketahui lebih akurat, karena dapat membandingkan dengan keadaan sebelum diberi perlakuan (Sugiyono, 2017:111).

Populasi adalah wilayah generalisasi yang terdiri atas obyek atau subyek yang mempunyai kualitas dan karakteristik tertentu yang ditetapkan oleh peneliti untuk dipelajari dan kemudian ditarik kesimpulan (Sugiyono, 2017:117). Jadi populasi dalam penelitian ini adalah semua siswa kelas II SDN 2 Nanga Man yang berjumlah 17 orang siswa.

Sampel adalah bagian dari jumlah dan karakteristik yang dimiliki oleh populasi (Sugiyono, 2017:118). Sampling jenuh adalah teknik penentuan sampel bila semua anggota populasi digunakan sebagai sampel. Hal ini dilakukan bila jumlah populasi relatif kecil. Jadi sampel dalam penelitian ini adalah siswa kelas II SDN 2 Nanga Man berjumlah 17 siswa dijadikan sampel penelitian, yaitu terdiri dari 9 siswa laki-laki dan 8 siswa perempuan.

Penelitian ini dilaksanakan di SDN 2 Nanga Man pada semester genaptahunpelajaran 2018/2019 dikelas II
Sekolah Dasar Negeri 2 Nanga Man. Sekolah ini adalah salah satu sekolah dasar yang ada di Kecamatan Pinoh Utara Kabupaten Melawi yang merupakan sekolah yang peneliti jadikan tempat penelitian.

Teknik pengumpulan data, merupakan "cara-cara yang dilakukan peneliti untuk memperoleh data yang valid, reliable dan obyektif" (Sugiyono, 2015:236). Dalam penelitian ini teknik pengumpulan data yang dipergunakan untuk mengukur gerakan salat siswa adalah teknik penilaian non tes berupa penilaian unjuk kerja.

Instrumen penelitian adalah suatu alat yang digunakan mengukur fenomena alam maupun sosial yang diamati (Sugiyono, 2017:148). Instrumen penelitian yang peneliti gunakan sebagai alat untuk mengumpulkan data praktik gerakan salat siswa dalam penelitian eksperimen ini adalah lembar pengamatan berupa daftar cek (check list). Lembar pengamatan gerakan salat siswa dipergunakan untuk mencocokan kesesuaian antara pengetahuan mengenai teori-teori di dalam praktik sehingga hasil evaluasinya lebih jelas.

Teknik analisis data pada penelitian ini menggunakan teknik analisis data uji Wilcoxon Match Pairs Test untuk data gerakan salat sebelum dan sesudah dilakukan treatmen. Uji Wilcoxon Match Pairs Test digunakan untuk menentukan 33| J P D, p-IS S N : 2252-8156, e - I S S N : 2579-3993 
ada tidaknya perbedaan rata-rata dua sample yang saling berhubungan (Sujarweni, 2015:74). Untuk itu digunakan rumus $\mathrm{z}$ dalam pengujiannya yang peneliti gunakan untuk uji hipotesis, ialah sebagai berikut:

$$
z=\frac{T-\mu_{T}}{\sigma_{T}}
$$

Keterangan :

$\mathrm{Z}=$ uji normal hitung.

$\mathrm{T}=$ jumlah jenjang/rangking yang

kecil.

$\mu_{T}=$ rataan jenjang/rangking

$\sigma_{T}=$ simpangan baku

jenjang/rangking

(Sugiyono, 2012:136)

\section{HASIL DAN PEMBAHASAN}

\section{Hasil Penelitian}

\section{Hasil Penelitian pada Tes Awal (Pretest)}

Hasil pengolahan data tes awal (pretest) kelas eksperimen dengan menggunakan statistik deskriptif menunjukan bahwa berdasarkan skor banyak gerakan salat yang bisa di praktikan siswa dengan baik dan benar. Maka diperoleh jumlah skor keseluruhan yaitu 223 dengan rata-rata 13,11, skor tertinggi 18 , terendah 8 . Sedangkan jika berdasarkan skor rata-rata, diperoleh jumlah keseluruan 929,1 dengan rata rata 54,65 skor rata-rata tertinggi adalah 75 nilai terendah 33,33.

\section{Hasil Penelitian pada Tes Akhir (Posttest)}

Hasil pengolahan data tes akhir (posttest) kelas eksperimen dengan menggunakan statistik deskriptif menunjukan bahwa berdasarkan skor banyaknya gerakan salat yang bisa dilakukan atau diperaktekan siswa dengan baik dan benar. Maka diperoleh jumlah skor keseluruhan yaitu 323 dengan rata-rata 19 gerakan salat bisa dilakukan oleh siswa, skor tertinggi 23 gerakan salat, terendah 14 gerakan salat. Sedangkan jika berdasarkan skor rata-rata, diperoleh jumlah keseluruan 1340,8 dengan rata rata 78,87 rata-rata skor tertinggi adalah 95,83 terendah 58,33.

Sebelum dan Sesudah Treatment (Perlakuan)

Besar peningkatan perbedaan sebelum dan sesudah diberi perlakuan dilihat berdasarkan rata-rata yang di peroleh oleh keseluruhan siswa yaitu sebesar 24.21 nilai selisih, dengan rata-rata pretest 54.65 dan posttets 78.87 .

Uji Hipotesis Uji Wilcoxon Match Pair Test

Tabel 1 Uji Wilcoxon Match Pair Test Statistics

\begin{tabular}{|l|r|}
\hline & \multicolumn{2}{|c|}{ Postest - Pretest } \\
\hline$Z$ & $-3.622^{2}$ \\
Asymp. Sig. (2-tailed) & .000 \\
\hline
\end{tabular}

34| J P D, p- I S S N : 2252-8156, e - I S S N : $2579-3993$ 
Berdasarkan output "Test Statistics", nilai $\mathrm{Z}$ hitung diketahui bernilai -3.622 dan diperoleh luas kurva untuk menentukan nilai tabel $\mathrm{Z}$ yaitu 0,4750 . Sehingga dapat ditentukan koordinat $\mathrm{Z}$ tabelnya bernilai 1.96 dapat dilihat pada lampiran halaman 120. Karena nilai $1.96>-3.622$ atau $\mathrm{Z}$ tabel > Z hitung sehingga keputusan hipotesis adalah "Hipotesis diterima".

Selain berdasarkan nilai $\mathrm{Z}$ dapat juga ditentukan berdasarkan nilai Alpha, diketahui Asymp.Sig (2-tailed) bernilai $0.000<0.05$, maka keputusanya hipotesis diterima. Artinya ada perbedaan antara praktik gerakan salat siswa untuk Pretest dan Posttest. Dengan demikian dapat disimpulkan bahwa" Terdapat perbedaan yang signifikan gerakan salat siswa sebelum dan sesudah penerapan metode demonstrasi berbantu media audio visual SDN 2 Nanga Man.”

\section{PEMBAHASAN}

Penelitian ini dilaksanakan di SDN 2 Nanga Man selama 2 hari, pembelajaran dilaksanakan dengan dua kali pertemuan (4x35) jam pembelajaran. Subjek dalam penelitian ini adalah siswa kelas II yang berjumlah 17 orang, dan objek dalam penelitian ini adalah pengaruh penerapan metode demonstrasi berbantu media audio visual terhadap gerakan salat siswa.

Tujuan dari penelitian ini adalah untuk mengetahui apakah terdapat perbedaan yang signifikan gerakan salat 35| J P D, p - I S S N : 2252 - 8156 , e - I S S N : 2579 - 3993 siswa sebelum dan sesudah penerapan metode demonstrasi berbantu media audio visual pada siswa kelas II SDN2 Nanga Man. Tahap awal dari penelitian,peneliti melakukan penyusunan intsrumen yang akan di gunakan dalam penelitian. Instrumen pada penelitian ini yaitu berupa lembar pengamatan pretest dan posttest, lembar pengamatan tersebut digunakan untuk mengukur gerakan salat siswa terhadap pembelajaran yang telah diberikan. Untuk mendapatkan instrumen yang baik maka di perlukan untuk pengujian kevalidan instrumen sebelum digunakan.

Lembar validasi ahli dibuat yang terdiri dari 5 aspek penilaian dengan 17 indikator. Sebelum lembar pengamatan digunakan peneliti terlebih dahulu melakukan pengujian validitas dengan indeks Aiken V. Dasar pengambilan keputusan indeks Aiken V yaitu: 1) Jika indeks kesepakatan $\leq 0,4$ maka validitasnya rendah; 2) Jika indeks kesepakatan diantara 0,4-0,8 maka validitasnya sedang; 3) Jika indeks kesepakatan $\geq 0,8$ maka validitasnya tinggi.

Pada hasil perhitungan dengan indeks Aiken $\mathrm{V}$ berdasarkan penilaian dua rater (ahli) diperoleh jumlah keseluruhan 95 dengan perolehan indeks Aiken $\mathrm{V}$ sebesar 0,78. Karena indeks kesepakatan berada diantara 0,4-0,8 maka validitasnya sedang. 
Uji instrumen selanjutnya yaitu uji reabilitas. Pengujian reabilitas dilakukan dengan menggunakan Crobatc'h Alpa pada program SPSS versi 17.0. Apabila nilai Crobatc'h Alpa > r tabel,maka soal dinyatakan reliabel. Dari hasil perhitungan diperoleh data bahwa lembar pengamatan dinyatakan reliabel.

Proses selanjutnya yaitu kegiatan inti dari penelitian yaitu proses pembelajaran. Peneliti melakukan tes awal (pretest) kepada siswa tanpa perlakuan,kemudian setelah pretest peneliti memberikan pelajaran dengan menggunakan metode demonstrasi berbantu media audio visual setelah itu peneliti melakukan posttest untuk mengukur gerakan salat siswa setelah mendapatkan perlakuan dengan metode demonstrasi berbantu media audio visual.

Selama proses pembelajaran peneliti menemukan beberapa permasalahan yang mebuat siswa kesulitan dalam mempraktikkan gerakan salat. Hal ini dikarenakan terdapat beberapa siswa yang baru mengetahui gerakan secara baik dan benar serta dikarenakan kecepatan siswa dalam menanggapi pembelajaran yang berbeda-beda. Maka dari itu untuk mengatasi permasalahan tersebut, peneliti berinisiatif untuk melakukan bimbingan khusus kepada siswa dalam mempraktikkan gerakan salat.

Gerakan salat siswa setelah diberikan perlakuan dengan menerapkan metode 36| J P D, p - I S S N : 2252-8156, e - I S S N : $2579-3993$ demonstrasi berbantu media audio visual lebih tinggi dari pada gerakan salat siswa sebelum mendapat perlakuan. Hal ini terlihat berdasarkan rata-rata yang di peroleh oleh keseluruhan siswa yaitu sebesar 24.21 nilai selisih, dengan rata-rata pretest 54.65 dan posttets 78.87 .

Dapat disimpulkan gerakan salat siswa setelah mendapat perlakuan lebih baik dibandingkan dengan sebelum diberi perlakuan.Data gerakan salat siswa selanjutnya dilakukan pengujian hipotesis. Uji hipotesis menggunakan uji Wilcoxon Match Pair Testdengan program SPSS versi 17.0. Berdasarkan output "Test Statistics", nilai Z hitung diketahui bernilai -3.622 dan berdasarkan hasil perhitungan diketahui Z table bernilai 1.96. Karena nilai $1.96>-3.622$ atau $\mathrm{Z}$ table $<\mathrm{Z}$ hitung sehingga keputusan hipotesis adalah "Hipotesis diterima". Artinya ada perbedaan antara praktik gerakan salat siswa untuk Pretest dan Posttest. Dengan demikian dapat disimpulkan bahwa terdapat perbedaan yang signifikan gerakan salat siswa sebelum dan sesudah penerapan metode demonstrasi berbantu media audio visual SDN 2 Nanga Man.

\section{SIMPULAN}

Berdasarkan masalah yang dirumuskan, pembahasan dan analisis data dapat ditarik beberapa kesimpulan, sebagai berikut: 
Pertama, kemampuan awal siswa sebelum diterapkan metode demonstrasi berbantuan media audio visual yang terlihat dari nilai pretest menunjukan bahwa siswa kesulitan dalam mengenal dan membedakan rangkaian gerakan salat, akan tetapi setelah diterapkan metode demonstrasi berbantuan media audio visual siswa kemudian dapat mengenal dan membedakan setiap rangkaian gerakan salat.

Kedua, gerakan salat siswa sebelum penerapan metode demonstrasi berbantu media audio visual dengan jumlah siswa 17 orang diperoleh rata-rata 54,65.

Ketiga, gerakan salat siswa sebelum penerapan metode demonstrasi berbantu media audio visual dengan jumlah siswa 17 orang diperoleh rata-rata 78,87.

Keempat, berdasarkan uji hipotesis, maka hipotesis diterima. Karena nilai $1.96>$ 3.622 atau $\mathrm{Z}$ table $>\mathrm{Z}$ hitung. Dengan demikian dapat disimpulkan bahwa" Terdapat perbedaan yang signifikan gerakan salat siswa sebelum dan sesudah penerapan metode demonstrasi berbantu media audio visual SDN 2 Nanga Man.”

\section{DAFTARPUSTAKA}

Huda, M. 2017. Model-Model Pengajaran dan Pembelajaran. Yogyakarta: Pustaka Pelajar.

Sugiyono. 2012. Statistika Untuk Penelitian. Bandung: Alfabeta.

Sugiyono. 2015. Metode Penelitian Tindakan Komprehensif. Bandung: Alfabeta.

Sugiyono. 2017. Metode Penelitian Pendidikan Pendekatan Kuantitatif, Kualitatif Dan R\&D. Bandung: Alfabeta.

Susanto, A. 2016. Teori Belajar dan Pembelajaran di Sekolah Dasar. Jakarta: Prenada Media Group.

Sujarweni, W. 2015. SPSS Untuk Penelitian. Yogyakarta: Pustaka Baru Press. 